\title{
Impact of Body Mass Index on the relationship of epicardial adipose tissue to metabolic syndrome and coronary artery disease in an Asian population
}

\author{
Jin-Sun Park ${ }^{+1}$, Sung-Gyun Ahn+2, Jung-Won Hwang ${ }^{+1}$, Hong-Seok Lim¹, Byoung-Joo Choi ${ }^{+1}$, So-Yeon Choit1, \\ Myeong-Ho Yoon ${ }^{+1}$, Gyo-Seung Hwang ${ }^{+1}$, Seung-Jea Tahk ${ }^{\dagger 1}$ and Joon-Han Shin*1
}

\begin{abstract}
Background: In a previous study, we demonstrated that the thickness of epicardial adipose tissue (EAT), measured by echocardiography, was increased in patients with metabolic syndrome (MS) and coronary artery disease (CAD). Several studies on obese patients, however, failed to demonstrate any relationship between EAT and CAD. We hypothesized that body mass index (BMI) affected the link between EAT and MS and CAD.

Methods: We consecutively enrolled 643 patients (302 males, 341 females; $59 \pm 11$ years), who underwent echocardiography and coronary angiography. The EAT thickness was measured on the free wall of the right ventricle at the end of diastole. All patients were divided into two groups: high BMl group, $\geq 27 \mathrm{~kg} / \mathrm{m}^{2}(\mathrm{n}=165)$, and non-high BMl group, $<27 \mathrm{~kg} / \mathrm{m}^{2}(\mathrm{n}=478)$.

Results: The median and mean EAT thickness of 643 patients were $3.0 \mathrm{~mm}$ and $3.1 \pm 2.4 \mathrm{~mm}$, respectively. In the nonhigh BMI group, the median EAT thickness was significantly increased in patients with MS compared to those without MS (3.5 vs. $1.9 \mathrm{~mm}, \mathrm{p}<0.001$ ). In the high BMl group, however, there was no significant difference in the median EAT thickness between patients with and without MS ( 3.0 vs. $2.5 \mathrm{~mm}, \mathrm{p}=0.813$ ). A receiver operating characteristic (ROC) curve analysis predicting MS revealed that the area under the curve (AUC) of the non-high BMI group was significantly larger than that of the high BMl group ( 0.659 vs. $0.506, p=0.007$ ). When compared to patients without $C A D$, patients with CAD in both the non-high and high BMI groups had a significantly higher median EAT thickness ( $3.5 \mathrm{vs} .1 .5 \mathrm{~mm}, \mathrm{p}$ $<0.001$ and 4.0 vs. $2.5 \mathrm{~mm}, \mathrm{p}=0.001$, respectively). However, an ROC curve analysis predicting CAD revealed that the AUC of the non-high BMl group tended to be larger than that of the high BMl group (0.735 vs. 0.657, $p=0.055)$.

Conclusions: While EAT thickness was significantly increased in patients with MS and CAD, the power of EAT thickness to predict MS and CAD was stronger in patients with $\mathrm{BMI}<27 \mathrm{~kg} / \mathrm{m}^{2}$. These findings showed that the measurement of EAT thickness by echocardiography might be especially useful in an Asian population with a non-high BMI, less than 27 $\mathrm{kg} / \mathrm{m}^{2}$.
\end{abstract}

\section{Background}

Central obesity (visceral adipose tissue) correlates strongly with the development of metabolic syndrome (MS) and coronary artery disease (CAD) [1]. There are ways to estimate visceral adipose tissue (VAT). Recently, there are several reports that proposed echocardiographic epicardial adipose tissue (EAT) as an easy and

* Correspondence: shinjh@ajou.ac.kr

1 Department of Cardiology, Ajou University School of Medicine, Suwon, Korea + Contributed equally

Full list of author information is available at the end of the article reliable imaging indicator of VAT. It is widely known that EAT thickness measured by echocardiography has a good correlation with abdominal adipose tissue measured by computed tomography $(\mathrm{CT})$ and magnetic resonance imaging (MRI) [2,3].

In our previous study, the EAT thickness increased linearly as the MS score increased and the EAT was thicker in patients with MS than in those without MS. The EAT was thicker in patients with significant CAD than in those without CAD. We suggested that EAT thickness measured by echocardiography was a good surrogate 
marker for MS and CAD $[3,4]$. In another study, EAT thickness was also related to MS and the presence and extent of CAD [5].

Several groups have failed to demonstrate the correlation between EAT and CAD. Chaowalit et al. reported that EAT thickness is not associated with the presence, extent or severity of CAD in patients [6]. Gorter et al. reported that neither pericardial fat nor visceral abdominal fat correlated with CAD in patients with body mass index (BMI) $\geq 25 \mathrm{~kg} / \mathrm{m}^{2}$ [7]. In these reports, the subjects were relatively obese compared with the subjects in our previous study. In our study, the mean BMI of the subjects was $25.2 \pm 3.1 \mathrm{~kg} / \mathrm{m}^{2}$. In the report of Chaowalit et al., the mean BMI of the subjects was $28.8 \pm 5.5 \mathrm{~kg} / \mathrm{m}^{2}[6]$. The inconsistent results regarding the correlation between EAT and CAD might be due to differences in BMI of the study population. In one study, the correlation between pericardial fat and coronary plaque was seen in the non-obese patients but not in the overweight patients [8]. To evaluate the correlation between pericardial fat and $\mathrm{CAD}$, it has been suggested that it is necessary to divide study subjects according to the degree of obesity, as obesity itself is frequently associated with various metabolic and circulatory factors and is known to be an independent risk factor for CAD [9]. Mazur et at. failed to demonstrate the correlation between EAT and MS. In that report, the subjects included obese children with BMI > 97 percentile as defined by the International Obesity Task Force $[10,11]$. In 2004, Kip et al. reported that the clinical effects of VAT on patients with MS differed between the normal BMI group and the obese group. In that study, the patients with MS and normal BMI had poorer clinical outcome compared to the patients with MS who were obese [12]. We hypothesized that the predicting ability of EAT thickness for MS and CAD is affected by BMI.

\section{Methods}

\section{Study population}

The EAT thickness was measured consecutively in 643 patients (mean age $59 \pm 11$ years; 302 males, 341 females) who underwent their first coronary angiography due to chest pain. The medical records of all patients were retrospectively reviewed after informed consent was obtained from patients. EAT has been proposed as a source of several inflammatory mediators [13-15]. We tried to exclude the acute systemic inflammatory effect to avoid confounding the role of EAT and diagnosis of MS. We excluded patients from the study if they had any of the following: active inflammation, a history of prior revascularization, heart failure, cardiomyopathy or acute myocardial infarction. We identified MS if there were more than 3 of 5 criteria based on the updated Adult Treatment Panel III (ATP III) guidelines. The MS score was defined as the number of criteria present. Adjusting values specifically for an Asian population, central obesity was defined as waist circumference of $\geq 90 \mathrm{~cm}$ in men and $\geq 80 \mathrm{~cm}$ in women [16]. Upon quantitative analysis of the coronary angiograms, significant $C A D$ was considered to be the presence of one or more stenoses, $\geq 50 \%$ in diameter, of a major epicardial vessel. The major epicardial vessels were defined as the left main coronary artery that divides into the left anterior descending and circumflex branches, and the right coronary artery.

\section{Measurement of echocardiographic epicardial adipose tissue}

Two-dimensional transthoracic echocardiography was performed. Recordings of six cycles of the two-dimensional parasternal long-axis were obtained. We enlarged each view for better visualization and accurate measurement of EAT thickness. The measurement of EAT thickness was done offline through the DICOM system and performed on the free wall of the right ventricle (RV) in the still image of a 2-D echocardiogram at end diastole on the parasternal long-axis. We preferred the area of above the RV to measure EAT thickness, because this area is recognized as having the thickest EAT layer. In addition, the parasternal long-and short-axis views allow the most accurate measurement of EAT thickness with optimal cursor beam orientation in each view. We measured the thickest point of EAT in each cycle. The average value of the EAT thickness was calculated (Figure 1).

\section{Coronary angiography}

Quantitative coronary angiographic analysis was performed by one experienced technician who was unaware of the patients' clinical information. Angiographic data were analyzed for the presence of CAD.

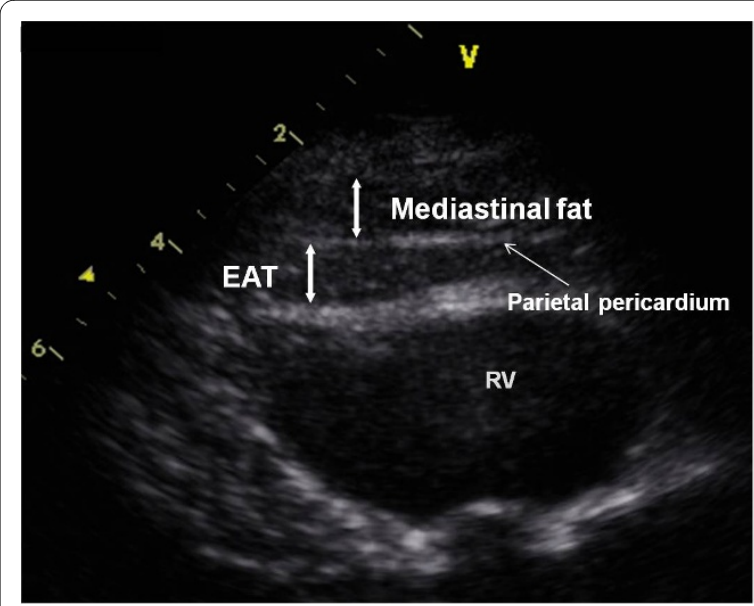

Figure 1 Echocardiographic measurement of epicardial adipose tissue thickness. Parasternal long-axis view at the mitral valve level. EAT, epicardial adipose tissue; RV, right ventricle 


\section{Statistical analysis}

The SPSS 12.0 (SPSS inc., Chicago, Illinois, USA) statistical software package was used for all calculations. Data are shown as the mean \pm standard deviation (SD) and the median values for continuous variables and as percentages for categorical variables. $\mathrm{p}<0.05$ indicates statistical significance. We compared the characteristics of patients who had BMI $\geq 27 \mathrm{~kg} / \mathrm{m}^{2}$ (high BMI group) to those with $\mathrm{BMI}<27 \mathrm{~kg} / \mathrm{m}^{2}$ (non-high BMI group). Comparisons of continuous variables were performed using the unpaired Student $t$ test. As the skewness of the EAT thickness was 0.749 ( $\mathrm{p}<0.001$ ) using the Kolmogrov-Smirnov test, comparisons of the EAT thickness according to the presence of MS in the high and non-high BMI groups and the presence of CAD in 2 groups were performed using the Wilcoxon rank-sum test rather than the parametric test. Comparisons of the EAT thickness according to the MS score were done using the Kruskal-Wallis test. A receiver operation characteristic (ROC) curve analysis was used to assess the discrimination of MS and CAD based on the EAT thickness according to the BMI. Medcalc 10.4.8 (Medcalc software inc., Mariakerke, Belgium) statistical software was used for comparing the area under curve (AUC) of the ROC curve between groups.

One sample paired t test was performed to evaluate inter- and intraobserver variability in the measurement of EAT from 30 randomly selected subjects.

\section{Results}

\section{Clinical characteristics}

Clinical characteristics according to BMI are summarized in Table 1. Seventy-four percent of patients were included in the non-high BMI group. The non-high BMI group consisted of 478 patients (252 males) with a mean age of $59 \pm 11$ years. Forty-nine percent of non-high BMI group met the criteria of the MS. The high BMI group was consisted of 165 patients (80 males) with a mean age of $59 \pm$ 11 years. Eighty-one percent of the high BMI group was diagnosed with MS.

Compared to the non-high BMI group, subjects in the high BMI group had significantly higher rates of hypertension, diabetes and metabolic syndrome and higher levels of total cholesterol, LDL-cholesterol and triglycerides.

The median and mean EAT thickness of 643 patients were $3.0 \mathrm{~mm}$ and $3.1 \pm 2.4 \mathrm{~mm}$, respectively. In the nonhigh BMI group, the median and mean EAT thickness were $2.8 \mathrm{~mm}$ and $3.0 \pm 2.4 \mathrm{~mm}$, respectively. In the high BMI group, the median and mean EAT thickness were 3.0 $\mathrm{mm}$ and $3.5 \pm 2.4 \mathrm{~mm}$, respectively. The median EAT thickness was significantly increased in the high BMI group compared to that of the non-high BMI group (3.0 vs. $2.8 \mathrm{~mm}, \mathrm{p}=0.01)$. The absolute values of the mean paired differences were $0.0200 \pm 0.39637, \mathrm{p}=0.773$ and $0.0033 \pm 0.46866, \mathrm{p}=0.969$ for inter- and intraobserver variability of the EAT measurement, indicating good reproducibility.

\section{Epicardial adipose tissue thickness as a predictor of metabolic syndrome according to body mass index}

The median EAT thickness was significantly increased in patients with MS compared to those without MS (3.3 vs. $2.0 \mathrm{~mm}, \mathrm{p}<0.001)$. EAT thickness also increased with an increase in the number of MS components $(\mathrm{p}<0.001)$.

In the non-high BMI group, the median EAT thickness was significantly increased in patients with MS compared to those without MS (3.5 vs. $1.9 \mathrm{~mm}, \mathrm{p}<0.001$, Figure 2). The median EAT thickness values for those with $0,1,2,3$, 4 , or 5 MS components were 1.3, 1.7, 2.0, 3.5, 3.5, and 3.2 $\mathrm{mm}$, respectively. The median EAT thickness significantly increased with an increase in the number of MS components $(\mathrm{p}<0.001$, Figure 3-A).

In the high BMI group, the median EAT thickness was not significantly increased in patients with MS compared to those without MS ( 3.0 vs. $2.5 \mathrm{~mm}, \mathrm{p}=0.813$, Figure 2 ). The median EAT thickness values for subjects with 0,1 , 2,3 , 4, or 5 MS components were $2.5,2.3,3.3,3.0,3.0$, and $4.5 \mathrm{~mm}$, respectively. The median EAT thickness did not increase with an increase in the number of MS components $(\mathrm{p}=0.121$, Figure 3-B).

The ROC curves of the EAT thickness in predicting MS yielded an AUC of 0.659 in the non-high BMI group and 0.506 in the high BMI group. When comparing the AUC of the 2 groups, the AUC to predict MS was significantly higher in the non-high BMI group compared to the high BMI group ( $\mathrm{p}=0.007$, Figure 4$)$.

\section{Epicardial adipose tissue thickness as a predictor of coronary artery disease according to body mass index}

The median EAT thickness was significantly increased in patients with CAD compared to patients without CAD (1.7 vs. $3.5 \mathrm{~mm}, \mathrm{p}<0.001)$. When compared to subjects without $\mathrm{CAD}$, patients with $\mathrm{CAD}$ in both the non-high and high BMI groups had a median EAT thickness that was significantly increased ( 3.5 vs. $1.5 \mathrm{~mm}, \mathrm{p}<0.001$ and 4.0 vs. $2.5 \mathrm{~mm}, \mathrm{p}=0.001$, respectively, Figure 5). In addition to well-known CAD risk factors, such as age, smoking, hypertension, and diabetes, EAT thickness was an independent factor associated with CAD in both groups (Table 2). The ROC curves of the EAT thickness in predicting CAD yielded an AUC of 0.657 in the non-high $\mathrm{BMI}$ group and 0.735 in the high $\mathrm{BMI}$ group. When comparing the AUC of the 2 groups, the ROC curve analysis predicting CAD revealed that the AUC of the BMI $<27$ $\mathrm{kg} / \mathrm{m}^{2}$ group tended to be larger than that of the BMI $\geq 27$ $\mathrm{kg} / \mathrm{m}^{2}(\mathrm{p}=0.055$, Figure 6).

\section{Discussion}

The present study demonstrated that the power of EAT thickness measured by echocardiography to predict MS 
Table 1: Baseline characteristics according to body mass index $(n=643)$

\begin{tabular}{|c|c|c|c|}
\hline Characteristics & $\begin{array}{l}\mathrm{BMI}<27 \mathrm{~kg} / \mathrm{m}^{2} \\
(\mathrm{n}=478)\end{array}$ & $\begin{array}{l}B M I \geq 27 \mathrm{~kg} / \mathrm{m}^{2} \\
(\mathrm{n}=165)\end{array}$ & $\mathbf{p}$ \\
\hline Male, No & $252(53 \%)$ & $80(48 \%)$ & NS \\
\hline Age (year-old) & $59 \pm 11$ & $59 \pm 11$ & NS \\
\hline \multicolumn{4}{|l|}{ EAT thickness (mm) } \\
\hline Mean \pm SD & $3.0 \pm 2.4$ & $3.5 \pm 2.4$ & 0.01 \\
\hline Median & 2.8 & 3.0 & 0.01 \\
\hline Body Mass Index (kg/m²) & $23.7 \pm 2.4$ & $29.0 \pm 2.1$ & $<0.001$ \\
\hline \multicolumn{4}{|l|}{ Waist circumference $(\mathrm{cm})$} \\
\hline Male & $87.0 \pm 8.0$ & $97.1 \pm 7.5$ & $<0.001$ \\
\hline Female & $84.7 \pm 9.1$ & $95.0 \pm 7.6$ & $<0.001$ \\
\hline Total cholesterol (mg/dl) & $170.6 \pm 35.3$ & $182.32 \pm 39.2$ & 0.001 \\
\hline LDL cholesterol (mg/dl) & $97.0 \pm 30.0$ & $104.4 \pm 33.7$ & 0.025 \\
\hline Triglyceride (mg/dl) & $142.1 \pm 83.3$ & $183.1 \pm 109.5$ & $<0.001$ \\
\hline \multicolumn{4}{|l|}{ HDL cholesterol (mg/dl) } \\
\hline Male & $44.0 \pm 10.7$ & $40.3 \pm 9.2$ & 0.013 \\
\hline Female & $48.3 \pm 12.7$ & $47.1 \pm 11.3$ & NS \\
\hline Fasting glucose (mg/dl) & $115.0 \pm 33.9$ & $120.0 \pm 43.4$ & NS \\
\hline Hypertension, No & $313(66 \%)$ & $125(76 \%)$ & 0.012 \\
\hline Diabetes, No & $295(62 \%)$ & $128(78 \%)$ & $<0.001$ \\
\hline Smoking, No & $156(33 \%)$ & $41(25 \%)$ & 0.048 \\
\hline Metabolic Syndrome, No & $243(49 \%)$ & $133(81 \%)$ & $<0.001$ \\
\hline Metabolic Score & $2.5 \pm 1.3$ & $3.3 \pm 1.0$ & $<0.001$ \\
\hline Coronary Artery Disease, No & $247(52 \%)$ & $74(45 \%)$ & NS \\
\hline Normal \& minimal CAD & $230(48 \%)$ & $91(55 \%)$ & NS \\
\hline 1 vessel & $111(23 \%)$ & $31(19 \%)$ & NS \\
\hline 2 vessel & $69(14 \%)$ & $24(15 \%)$ & NS \\
\hline 3 vessel & $65(14 \%)$ & $19(12 \%)$ & NS \\
\hline \multicolumn{4}{|l|}{ Medication, No } \\
\hline Aspirin & $115(24 \%)$ & $37(22 \%)$ & NS \\
\hline Beta blockers & $49(10 \%)$ & $19(12 \%)$ & NS \\
\hline Calcium channel blockers & $89(19 \%)$ & $33(20 \%)$ & NS \\
\hline ACE inhibitors & $23(5 \%)$ & $4(2 \%)$ & NS \\
\hline AT II receptor blockers & $58(12 \%)$ & $22(13 \%)$ & NS \\
\hline Statins & $46(10 \%)$ & $22(13 \%)$ & NS \\
\hline Nitrates & $51(11 \%)$ & $16(10 \%)$ & NS \\
\hline Diuretics & $46(10 \%)$ & $18(11 \%)$ & NS \\
\hline
\end{tabular}

EAT, epicardial adipose tissue; $L D L$, low-density lipoprotein; $H D L$, high-density lipoprotein; $C A D$, coronary artery disease; $A C E$, angiotensin converting enzyme; AT, angiotensin; SD, standard deviation; NS, not significant

was stronger in patients with $\mathrm{BMI}<27 \mathrm{~kg} / \mathrm{m}^{2}$. Our results also demonstrated a strong correlation between EAT thickness and CAD, especially in patients with a non-high BMI. Our study might explain previous inconsistent results from various studies regarding the correlation between EAT and CAD [3,6,7,17]. Recently Gorter et al. reported that, in patients with $\mathrm{BMI}<27 \mathrm{~kg} / \mathrm{m}^{2}$, increased EAT volume and pericoronary fat volume as measured by $\mathrm{CT}$ were associated with $\mathrm{CAD}$ and extensive coronary artery calcium (CAC) [7]. Although we used a different 


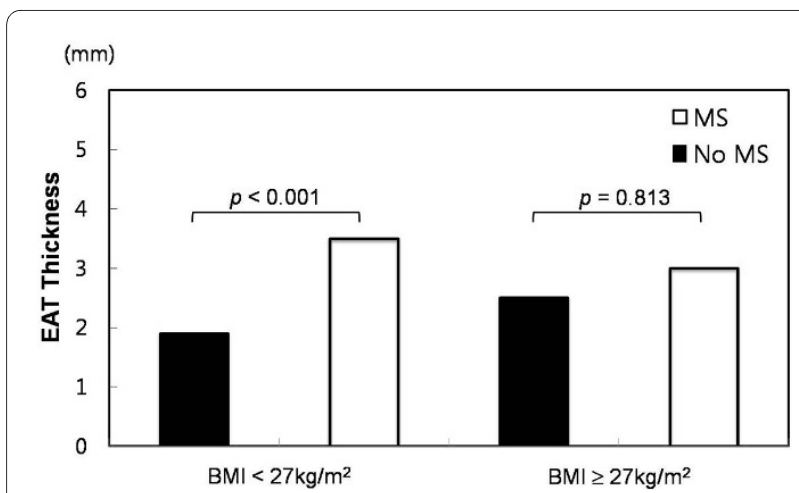

Figure 2 Distribution of the thickness of epicardial adipose tissue according to body mass index and metabolic syndrome.

way to evaluate EAT, using echocardiography to measure EAT thickness, the results were consistent with those of Gorter et al. In addition to these findings, we demonstrated that the predicting value of EAT thickness for MS might be more useful in patients with a non-high BMI. The results of our study suggest that different standards of EAT thickness according to BMI are needed to predict MS and CAD.

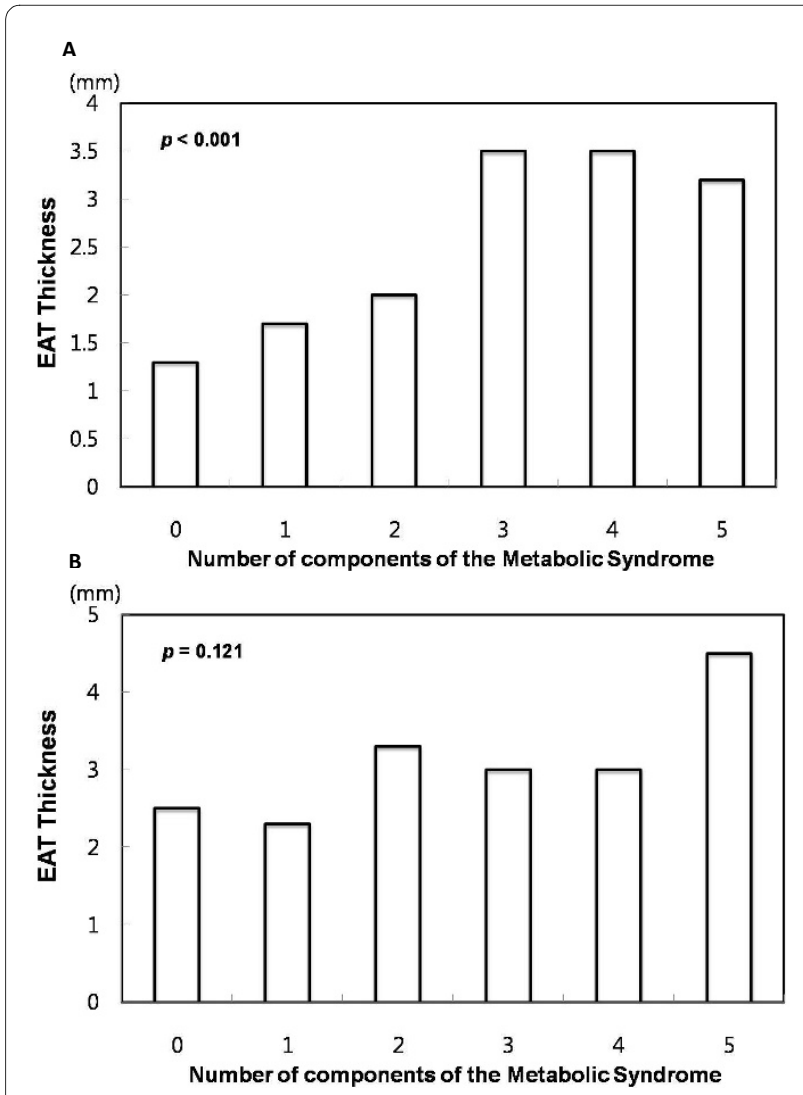

Figure 3 Distribution of the thickness of epicardial adipose tissue according to body mass index and metabolic score. (A) Non-high BMl group. (B) High BMl group.

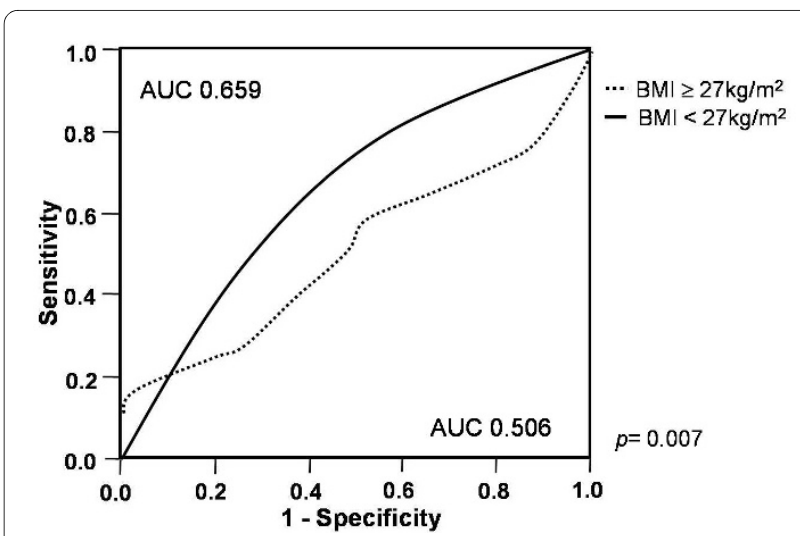

Figure 4 ROC curve analysis to demonstrate the discriminatory power of the thickness of epicardial adipose tissue in the diagnosis of metabolic syndrome according to body mass index. AUC, the area under the curve

In the present study, we used $27 \mathrm{~kg} / \mathrm{m}^{2}$ as the cut-off point; any number equal to 27 and above was the BMI for obesity. The relative percentage of body fat at different BMIs clearly varies within populations. The corresponding cut-off point for obesity, based on the assumption that the percentage of body fat in the Asian population is the same as the percentage of body fat in the Western population, was lower than the existing WHO cut-off point for obesity, $30 \mathrm{~kg} / \mathrm{m}^{2}$ [18]. Western studies have reported that a BMI $\geq 30 \mathrm{~kg} / \mathrm{m}^{2}$ group has a greater risk of death caused by cardiovascular diseases $[19,20]$. Some recent studies on Asian populations showed that low BMI influences cardiovascular diseases [18,21]. In 2007, the Kangwha Cohort Study reported that the risk of cardiovascular diseases was significantly increased in the BMI $\geq$ $27 \mathrm{~kg} / \mathrm{m}^{2}$ group in the Korean population [22]. This study included the Korean population, so we decided that the cut-off point for obesity was $27 \mathrm{~kg} / \mathrm{m}^{2}$ instead of $30 \mathrm{~kg}$ / $\mathrm{m}^{2}$.

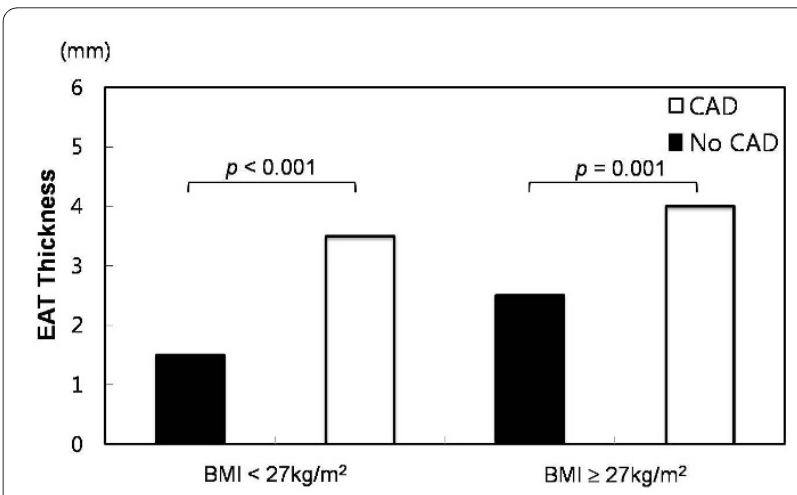

Figure 5 Distribution of the thickness of epicardial adipose tissue according to body mass index and coronary artery disease. 


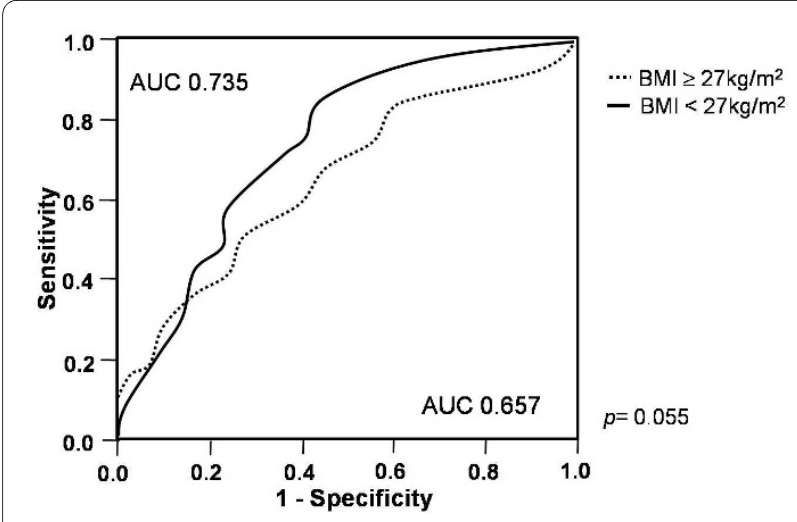

Figure 6 ROC curve analysis to demonstrate the discriminatory power of the thickness of epicardial adipose tissue in the diagnosis of coronary artery disease according to body mass index. AUC, the area under the curve

Several biomolecular studies in humans have shown that EAT is metabolically active and an important source of both pro-inflammatory adipokines, such as tumor necrosis factor- $\alpha$, interleukin 1, interleukin 6 and nerve growth factor, and anti-inflammatory adipokines, such as adiponectin and adrenomedullin [13-15]. The regulation and metabolism of pro- and anti-inflammatory mediators secreted by EAT have been linked to insulin sensitivity [23]. EAT has been shown to express a pathogenic mRNA profile of pro-inflammatory adipokines in patients with CAD [13]. One study showed that expression of adiponectin, an anti-inflammatory adipokine, in EAT was significantly lower in patients with CAD compared to those without CAD [14]. EAT thickness has also been shown to be related to markers of insulin resistance and inflammation [2]. For example, one study demonstrated that obesity leads to adipocyte hypertrophy, which increases the secretion of pro-inflammatory adipokines and decreases the secretion of anti-inflammatory adipokines by EAT [23]. The change of EAT thickness by obesity might have obscured the difference between patients with and without CAD, or with and without MS, in the high BMI group of our study.

The second possible explanation for the weak correlation between the EAT thickness and presence of MS and $\mathrm{CAD}$ in the high BMI group, might be the different proportion of the EAT to total amount of VAT according to BMI. Patients with high BMI generally have more VAT, which includes EAT. In the high BMI group, the EAT might make up a smaller proportion of the total VAT

Table 2: Multiple logistic analysis of coronary artery disease risk factors

(A) Non-high BMI group $(\mathrm{n}=478)$

\begin{tabular}{lll}
\hline Risk factors & Odds ratio $(\mathbf{9 5 \%} \mathbf{C l})$ & p \\
\hline Age & & $<0.001$ \\
$\quad$ Male $45 \geq$ years & $2.847(1.603-5.057)$ & \\
$\quad$ Female $55 \geq$ years & & 0.043 \\
Smoking & $1.576(1.014-2.448)$ & $<0.001$ \\
Hypertension & $2.115(1.385-3.230)$ & 0.004 \\
Diabetes mellitus & $2.139(1.282-3.569)$ & $<0.001$ \\
EAT thickness $(\geq 3 \mathrm{~mm})$ & $3.504(2.297-5.346)$ & \\
\end{tabular}

(B) High BMI group $(\mathrm{n}=165)$

\begin{tabular}{lll}
\hline Risk factors & Odds ratio $\mathbf{( 9 5 \%} \mathbf{C l})$ & p \\
\hline Age & $6.531(2.089-20.420)$ & \\
$\quad$ Male $45 \geq$ years & & \\
$\quad$ Female $55 \geq$ years & $1.775(0.763-4.129)$ & 0.001 \\
Smoking & $1.276(0.6-2.712)$ & 0.183 \\
Hypertension & $2.687(1.222-5.911)$ & 0.527 \\
Diabetes mellitus & $2.341(1.136-4.827)$ & 0.014 \\
EAT thickness $(\geq 3 \mathrm{~mm})$ & 0.021 \\
\hline
\end{tabular}

EAT, epicardial adipose tissue; $\mathrm{Cl}$, confidence interval 
compared to the non-high BMI group. In the high BMI group, the EAT thickness by echocardiography might not be representative of the total VAT owing to its smaller proportion of the total VAT. That reason might attenuate the predictive value of EAT thickness by echocardiography for MS and CAD in the high BMI group. Further study is necessary to clarify the different roles of EAT according to BMI. Considering racial and gender differences in addition to BMI, further study will be necessary to set the standards of EAT thickness by echocardiography.

There are several limitations to the present study. First, the study population was highly selective for those who underwent their first coronary angiography due to chest pain. Therefore, the results of the study could not be applied to the general population. Also, it was a crosssectional study, not a cohort study. In a community-based prospective cohort study, it was reported that pericardial fat predicts incident coronary heart disease independent of conventional risk factors. They evaluated the correlation between pericardial fat and CAD without dividing study subjects according to the degree of obesity [24]. A prospective cohort study might be needed to elucidate the different predicting power of EAT for MS and CAD according to BMI in the general population. Second, EAT thickness by echocardiography does not exactly represent the amount of total EAT. Even though echocardiography is not the optimal method for quantification of EAT, our previous study showed that EAT thickness measured by echocardiography has a good correlation with the total amount of EAT [25]. EAT is true visceral fat deposited around the heart. Epicardial, mesenteric, and omental fat all share the same origin from the splanchnopleurituc mesoderm associated with the gut [26]. EAT thickness measured by echocardiography provides a sensitive and specific measurement of true visceral fat, avoiding the confounding effect caused by subcutaneous fat [27]. As echocardiography is frequently performed in high-risk cardiac patients, EAT thickness measured by echocardiography may be readily available at no extra cost. Therefore, EAT thickness by echocardiography could be applied as an easy and reliable imaging indicator of VAT without radiation exposure $[2,3]$.

\section{Conclusions}

While EAT thickness was significantly increased in patients with MS and CAD regardless of BMI, the power of EAT to predict MS and CAD was stronger in patients with BMI $<27 \mathrm{~kg} / \mathrm{m}^{2}$. These findings showed that the measurement of EAT thickness by echocardiography might be useful in patients with non-high BMI, especially one less than $27 \mathrm{~kg} / \mathrm{m}^{2}$.

\section{Competing interests}

The authors declare that they have no competing interests.

\section{Authors' contributions}

All authors participated in the design and coordination of the study, reviewed the analysis and took part in writing the manuscript. They also read and approved the final manuscript.

\section{Acknowledgements}

We express our gratitude to Minje Sung, PhD in Ajou University, School of Business Administration for help with statistical analysis and SPSS programming.

\section{Author Details}

1Department of Cardiology, Ajou University School of Medicine, Suwon, Korea and 2Division of Cardiology, Yonsei University Wonju College of Medicine, Wonju, Korea

Received: 26 April 2010 Accepted: 7 July 2010

Published: 7 July 2010

\section{References}

1. National Cholesterol Education Program (NCEP) Expert Panel on Detection, Evaluation, and Treatment of High Blood Cholesterol in Adults (Adult Treatment Panel III): Third Report of the National Cholesterol Education Program (NCEP) Expert Panel on Detection, Evaluation, and Treatment of High Blood Cholesterol in Adults (Adult Treatment Panel III) final report. Circulation 2002, 106:3143-3421.

2. lacobellis G, Ribaudo MC, Assael F, Vecci E, Tiberti C, Zappaterreno A, Di Mario U, Leonetti F: Echocardiographic epicardial adipose tissue is related to anthropometric and clinical parameters of metabolic syndrome: a new indicator of cardiovascular risk. J Clin Endocrinol Metab 2003, 88:5163-5168.

3. Ahn SG, Lim HS, Joe DY, Kang SJ, Choi BJ, Choi SY, Yoon MH, Hwang GS, Tahk SJ, Shin JH: Relationship of epicardial adipose tissue by echocardiography to coronary artery disease. Heart 2008, 94:e7

4. Baik SH, Ahn SG, Choi JH, Koh BR, Yoo JH, Kang SJ, Choi BJ, Choi SY, Yoon $\mathrm{MH}$, Tahk SJ, Shin JH: The relationship of epicardial adipose tissue to metabolic syndrome and cardiovascular risk factors. Korean J Med 2007, 72:290-297.

5. Eroglu S, Sade LE, Yildirir A, Bal U, Ozgul AS, Bozbas H, Anydinalp A, Muderrisoglu $\mathrm{H}$ : Epicardial adipose tissue thickness by echocardiography is a marker for the presence and severity of coronary artery disease. Nutr Metab Cardiovasc Dis 2009, 19(3):211-217.

6. Chaowalit N, Somers VK, Pellikka PA, Rihal CS, Lopez-Jimenez F: Subepicardial adipose tissue and the presence and severity of coronary artery disease. Atherosclerosis 2006, 186(2):354-359.

7. Gorter PM, de Vos AM, van der Graaf Y, Stella PR, Doevendans PA, Meijs MF, Prokop M, Visseren FL: Relation of epicardial and pericoronary fat to coronary atherosclerosis and coronary artery calcium in patients undergoing coronary angiography. Am J Cardiol 2008, 102:380-385.

8. Yong HS, Kim EJ, Seo HS, Kang EY, Kim YK, Woo OH, Han H: Pericardial fat is more abundant in patients with coronary atherosclerosis and even in the non-obese patients: evaluation with cardiac CT angiography. Int J Cardiovasc Imaging 2010, 26:53-62.

9. Taguchi R, Takasu J, Itani Y, Yamamoto R, Yokoyama K, Watanabe S, Masuda Y: Pericardial fat accumulation in men as a risk factor for coronary artery disease. Atherosclerosis 2001, 157:203-209.

10. Mazur A, Ostański M, Telega G, Malecka-Tendera E: Is epicardial fat tissue a marker of metabolic syndrome in obese children? Atheroscleorsis 2010 in press

11. Cole TJ, Bellizzi MC, Flegal KM, Dietz WH: Establishing a standard definition for child overweight and obesity worldwide international survey. BMJ 2000, 320:1240-1243

12. Kip KE, Marroquin OC, Kelley DE, Johnson BD, Kelsey SF, Shaw LJ, Rogers WJ, Reis SE: Clinical importance of obesity versus the metabolic syndrome in cardiovascular risk in women: a report from the Women's Ischemia Syndrome Evaluation (WISE) study. Circulation 2004, 17; 109(6):706-713.

13. Baker AR, Silva NF, Quinn DW, Harte AL, Pagano D, Bonser RS, Kumar S, McTernan PG: : Human epicardial adipose tissue expresses a pathogenic profile of adipocytokines in patients with cardiovascular disease. Cardiovasc Diabetol 2006, 5:1-7. 
14. Iacobellis G, Pistilli D, Gucciardo M, Leonetti F, Miraldi F, Brancaccio G, Gallo P, di Gioia CR: Adiponectin expression in human epicardial adipose tissue in vivo is lower in patients with coronary artery disease. Cytokine 2005, 29:251-255.

15. lacobellis $G$, Barbaro $G$ : The double role of epicardial adipose tissue as pro- and anti-inflammatory organ. Horm Metab Res 2008, 40(7):442-445.

16. Grundy SM, Cleeman JI, Daniels SR, Donato KA, Eckel RH, Franklin BA, Gordon DJ, Krauss RM, Savage PJ, Smith SC Jr, Spertus JA, Fernando Costa: Diagnosis and management of the metabolic syndrome: an American Heart Association/National Heart, Lung, and Blood Institute scientific statement. Circulation 2005, 112:2735-2752.

17. Jeong JW, Jeong MH, Yun KH, Oh SK, Park EM, Kim YK, Rhee SJ, Lee EM, Lee J, Yoo NJ, Kim NH, Park JC: Echocardiographic epicardial fat thickness and coronary artery disease. Circ J 2007, 71:536-539.

18. WHO expert consultation: Appropriate body-mass index for Asian populations and its implications for policy and intervention strategies. Lancet 2004, 363(9403):157-163.

19. Shaper AG, Wannamethee SG, Walker M: Body weight: implications for the prevention of coronary heart disease, stroke, and diabetes mellitus in a cohort study of middle aged men. BMJ 1997, 314:1311-1317.

20. Calle EE, Thun MJ, Petrelli JM, Rodriguez C, Heath CW Jr: Body-mass index and mortality in a prospective cohort of U.S. adults. NEJM 1999, 341:1097-1105.

21. Cui R, Iso H, Toyoshima H, Date C, Yamamoto A, Kikuchi S, Kondo T, Watanabe Y, Koizumi A, Wada Y, Inaba Y, Tamakoshi A, JACC Study Group: Body mass index and mortality from cardiovascular disease among Japanese men and women: the JACC study. Stroke 2005, 36(7):1377-1382.

22. Hong JS, Yi SW, Kang HC, Ohrr H: Body mass index and mortality in South Korean men resulting from cardiovascular disease: a Kangwha cohort study. Ann Epidemiol 2007, 17(8):622-627.

23. Karastergiou K, Mohamed-Ali V: The autocrine and paracrine roles of adipokines. Mol Cell Endocrinol 2010, 318:69-78.

24. Ding J, Hsu FC, Harris TB, Liu Y, Kritchevsky SB, Szklo M, Ouyang P, Espeland MA, Lohman KK, Criqui MH, Allison M, Bluemke DA, Carr JJ: The association of pericardial fat with incident coronary heart disease: the Multi-Ethnic Study of Atherosclerosis (MESA). Am J Clin Nutr 2009, 90(3):499-504.

25. Hwang JW, Choi UJ, Ahn SG, Lim HS, Kang SJ, Choi BJ, Choi SY, Yoon MH, Hwang GS, Tahk SJ, Shin JH, Kang DK: Echocardiographic plains reflecting total amount of epicardial adipose tissue as risk factor of coronary artery disease. J Cardiovasc Ultrasound 2008, 16(1):17-22.

26. Ho E, Shimada Y: Formation of the epicardium studied with the scanning electron microscope. Dev Biol 1978, 66(2):579-585.

27. lacobellis $G$, Singh $N$, Wharton $S$, Sharma AM: Substantial changes in epicardial fat thickness after weight loss in severely obese subjects. Obesity 2008, 16(7):1693-1697.

\section{Submit your next manuscript to BioMed Centra} and take full advantage of:

- Convenient online submission

- Thorough peer review

- No space constraints or color figure charges

- Immediate publication on acceptance

- Inclusion in PubMed, CAS, Scopus and Google Scholar

- Research which is freely available for redistribution

Submit your manuscript at www.biomedcentral.com/submit
C) Biomed Central 